\title{
Adsorption of As(III) and As(V) by Fe coated biochars and biochars produced from empty fruit bunch and rice husk
}

\begin{abstract}
The study was conducted to determine the adsorption capacity of commercially produced empty fruit bunch biochar (EFBB) and a rice husk biochar (RHB) for As(III) and As(V). The effects of coating the biochars with $\mathrm{Fe}$ (III) on adsorption of $\mathrm{As}(\mathrm{III})$ and $\mathrm{As}(\mathrm{V})$ were also studied. Batch equilibrium adsorption was employed to determine the adsorption capacity of the biochars for As(III) and (V). The adsorption data were fitted to the Langmuir adsorption model. The maximum adsorption capacity (Qmax) of both EFBB and RHB for As(III) was higher than for As(V). The Qmax of EFBB and RHB for As(III) was $18.9 \mathrm{mg}$ gī 1 and 19.3 $\mathrm{mg}$ gi 1, respectively. In contrast, the Qmax of EFBB and RHB for As(V) was only $5.5 \mathrm{mg}$ gī 1 and $7.1 \mathrm{mg}$ gī 1, respectively. Coating the EFBB and RHB with Fe(III) increased their Qmax values for both As(III) and As(V). The Qmax of Fe-coated EFBB (FC-EFBB) and Fecoated RHB (FC-RHB) for As(III) was $31.4 \mathrm{mg}$ gī 1 and $30.7 \mathrm{mg}$ gī 1, respectively. The Qmax of FC-EFBB and FC-RHB for As(V) was $15.2 \mathrm{mg}$ gī 1 and $16.0 \mathrm{mg}$ gī 1, respectively. Although the surface area of the EFBB (1.890 m2 gi 1) was much lower than the RHB's (25.161 m2 gi 1), its adsorption capacity for the As was not much different than the RHB, suggesting that oxygen-containing functional groups, zeta potentials, the amounts of functional groups, $\mathrm{O} / \mathrm{C}$ ratios, $(\mathrm{O}+\mathrm{N}) / \mathrm{C}$ ratios and polarity indices $[(\mathrm{O}+\mathrm{N}) / \mathrm{C}]$ were important in determining As adsorption by these biochars. The biochar surfaces were smooth before As adsorption and became coarser after As was adsorbed. The adsorption of As was confirmed by the EDS data. EFBB and RHB have potentials to be used as low cost adsorbents for removal of As(III) from waste water while FC-EFBB and FC-RH could be used for removal of both As(III) and As(V).
\end{abstract}

Keyword: Fe-coated biochar; Arsenic; Functional groups; Langmuir 